\title{
Lineamientos para la mejora del sistema de gestión de la calidad en entidades responsables de la movilidad en el Distrito Capital ${ }^{*}$
}

Guidelines for the quality management system improving in organizations responsible for mobility in the Capital District

Javier Día Acosta**

Secretaría Distrital de Movilidad

Gladys Espitia Peña****

Secretaría Distrital de Movilidad

Blanca Ofir Murillo Solarte*****

Secretaría Distrital de Movilidad

* Artículo de resultado de investigación.

** Ingeniero de Sistemas. Magíster en Calidad y Gestión Integral. Correo electrónico: Javier.diaz.acosta@gmail.com

****Contadora Pública. Magíster en Calidad y Gestión Integral. Correo electrónico: gespitiap@hotmail.com

**** Ingeniera Industrial. Magíster en Calidad y Gestión Integral. Correo electrónico: bofirmurillo@hotmail.com 


\section{RESUMEN}

La Secretaría Distrital de Movilidad (SDM) de Bogotá D.C. y la Empresa de Transporte Tercer Milenio S. A. (TRANSMILENIO), entidades responsables de la movilidad en el Distrito Capital, tienen implementado o certificado su sistema de gestión de la calidad, el cual se encuentra directamente relacionado con la satisfacción de las expectativas de los usuarios. En esta investigación, mediante una encuesta se determina la satisfacción de los usuarios con respecto a la movilidad, y a partir de los resultados obtenidos se formulan lineamientos, conclusiones y recomendaciones para la mejora continua del sistema de gestión de la calidad en las dos entidades responsables de la movilidad en el Distrito Capital.

Palabras clave: sistema de gestión de la calidad, mejoramiento continuo, percepción, satisfacción del usuario/ ciudadano.

\section{ABSTRACT}

The Secretaría Distrital de Movilidad (SDM) of Bogotá D.C. and the Empresa de Transporte Tercer Milenio (TRANSMILENIO), entities responsible for mobility in the capital district, have implemented or certified its quality management system, which is directly related to meeting the expectations of users. In this research satisfaction of users with regard to mobility it is determined by a survey, and from the results obtained, guidelines, conclusions and recommendations for the continuous improvement of the quality management system in the two entities responsible for mobility in the Capital District are formulated.

Keywords: Quality management system, continuous improvement, perception, user / citizen satisfaction.

\section{INTRODUCCIÓN}

Los resultados que se presentan en este escrito corresponden al ejercicio de medición de la satisfacción de los usuarios de las dos entidades más representativas en la movilidad en la ciudad de Bogotá: la Secretaría Distrital de Movilidad (SDM) y la Empresa de Transporte Tercer Milenio S. A. (TRANSMILENIO), medición que se realiza por medio de una encuesta diseñada con base en los criterios establecidos en las teorías de calidad de los autores Joseph Juran, Kaoru Ishikawa y Edwards W. Deming y en los principios de la Norma técnica de calidad en la gestión pública - NTCGP 1000:2009.

Los resultados de la encuesta se tomaron como base para la formulación de lineamientos y recomendaciones que se pueden replicar en beneficio de otras instituciones distritales y, en consecuencia, en satisfacción para la comunidad.

El planteamiento de la investigación se enfoca en resolver dos inquietudes, a saber: ¿qué percepción tienen los usuarios de los servicios prestados por TRASMILENIO y SDM en el Distrito Capital de Bogotá? y ¿qué lineamientos se proponen para la mejora continua del sistema de gestión de calidad (SGC) en TRASMILENIO y SDM, entidades del sector de la movilidad en el Distrito Capital de Bogotá?

Estos cuestionamientos son necesarios dadas las últimas tendencias en las estadísticas, como lo muestra la tabla 1.

La investigación se enmarcó en la Norma técnica de calidad para la gestión pública - NTCGP 1000: 2009 sin desconocer que en los antecedentes o en el estado del arte de esta norma se relacionan algunas teorías y movimientos hacia la calidad y el servicio a través del tiempo, las cuales se describe a continuación: 
Tabla 1. Número de PQRS radicados según fuentes disponibles, vigencias 2012 - 2014.

\begin{tabular}{|l|c|c|c|c|c|c|}
\hline \multirow{2}{*}{ Me canismos o fuentes para radicación de PQRS } & \multicolumn{2}{|c|}{2012} & \multicolumn{2}{|c|}{2013} & \multicolumn{2}{c|}{2014} \\
\cline { 2 - 7 } & $\begin{array}{c}\text { No. de } \\
\text { documentos }\end{array}$ & $\begin{array}{c}\text { Porcentaje } \\
\text { de variación }\end{array}$ & $\begin{array}{c}\text { No. de } \\
\text { documentos }\end{array}$ & $\begin{array}{c}\text { Porcentaje } \\
\text { de variación }\end{array}$ & $\begin{array}{c}\text { No. de } \\
\text { documentos }\end{array}$ & $\begin{array}{c}\text { Porcentaje } \\
\text { de variación }\end{array}$ \\
\hline $\begin{array}{l}\text { PQRS ingresados por el aplicativo de } \\
\text { correspondencia }\end{array}$ & 8690 & $118,23 \%$ & 10274 & $236,02 \%$ & 20510 & NA \\
\hline $\begin{array}{l}\text { PQRS ingresados por el aplicativo de } \\
\text { correspondencia }\end{array}$ & 6895 & $86,38 \%$ & 5956 & $136,39 \%$ & 9404 & NA \\
\hline Total PQRS & 15585 & $104,14 \%$ & 16230 & $184,31 \%$ & 29914 & $191,94 \%$ \\
\hline
\end{tabular}

Fuente: Secretaría Distrital de Movilidad.

Como antecedente de la Norma técnica de calidad (NTC) en Colombia, es conveniente mencionar que para el año 2002, los senadores Carlos Moreno de Caro y Alexandra Moreno Piraquive presentaron los proyectos de Ley 03 y 27, respectivamente (Gaceta, 2013); en el primero se solicita la adopción del Sistema de Gestión de Calidad en las entidades del Estado, y en el segundo se solicita implementar el Sistema de Gestión de Calidad y Eficiencia en las entidades del orden nacional con funciones públicas, pero no se refiere a la norma NTC ISO 9000, sino que se describen los objetivos, las características del sistema, los agentes obligados, los requisitos y pasos para su implementación y la existencia de una certificación de la calidad que no la limita a la NTC ISO 9000, aunque la incluye implícitamente.

La presente investigación se apoyó en las tres teorías Deming, Ishikawa y Juran, debido a que los tres autores mencionan el enfoque de los clientes y/o servicios como eje central de la calidad; además, fueron el fundamento en la Norma Técnica de Calidad para la Gestión Pública-NTCGP 1000, de la cual se tuvieron en cuenta sus principios, con base en las cuales se construyó el marco teórico de la investigación.

La teoría de Deming vincula principios como calidad del producto/servicio, ingenio en mercadeo, errores, defectos, deficiencias y fallas, innovación, mantenimiento e investigación, peticiones, quejas y reclamos, continuidad, valor agregado, capacitación/entrenamiento (Walton, 1988).

\section{La teoría de calidad total, de Kaoru Ishikawa, al} igual que la anterior teoría, genera impacto en el desarrollo y en la implementación de los sistemas de gestión de la calidad y de pertinencia para la investigación porque se centra en la NTCGP 1000. Los principios que contiene son calidad del producto y/o servicio, ingenio y mercadeo, errores, defectos, deficiencias y fallas, innovación, mantenimiento e investigación, peticiones, quejas y reclamos, continuidad, valor agregado, capacitación y/o entrenamiento (Ishikawa, 1997).

La teoría de la planificación para la calidad, de Joseph Juran, tiene como postulados (Juran, 1990) la calidad del producto y/o servicio, errores, defectos, deficiencias y fallas, innovación, mantenimiento e investigación, quejas de los clientes, continuidad, valor agregado, capacitación y entrenamiento.

Apoyados en las anteriores definiciones de los teóricos, los investigadores establecieron sus propios enunciados para cada una de las categorías, siendo estás: 
- Calidad: "Diseñar, elaborar y cumplir a tiempo con la entrega del producto y/o servicio al cliente para que pueda satisfacer sus requerimientos".

- Ingenio en mercadeo: "Con mejor calidad, con precio más bajo y con un poco de ingenio en mercadeo, crearán un mercado y se mantendrán en el negocio".

- Errores, defectos, deficiencias y fallas: "La planeación y la administración de la calidad significan reducir desperdicios de materiales y productos rechazados, eliminar defectos o la reposición y compensación pagada a los clientes por las fallas, lo cual genera altos costos, incidiendo en el precio".

- Innovación, mantenimiento e investigación: "En las etapas de desarrollo de nuevos productos, debemos lograr que nos reconozcan como innovadores, de alta calidad y bajo costo, forjar relaciones de largo plazo con los clientes".

- Peticiones, quejas y reclamos: "Los clientes o usuarios externos expresan su disgusto en forma de quejas o reclamaciones, las cuales son oportunidades, porque representan una ocasión para mejorar y reaplicar la calidad".

- Continuidad: "Crear constancia en la mejora de los productos y/o servicios y promover la delegación del control a los más bajos niveles posibles en la organización, cediendo la responsabilidad del autocontrol a los trabajadores".

- Valor agregado: "Simplemente tener satisfecho a nuestros clientes no es suficiente, se tiene que hacer algo mejor, es fundamental trabajar en equipo, en el diseño y en cada etapa del proceso mediante un mayor entendimiento de lo que necesita el cliente".
- Capacitación/Entrenamiento: "Estimular la educación y la automejora es lo que necesita una organización, dado que la educación y el reentrenamiento son inversiones en la gente, porque el propósito fundamental de la capacitación debería de ser el cambio de conducta más que la formación".

Algunos conceptos de interés para esta investigación son el trámite, la mejora continua y los sistemas de gestión de calidad.

El servicio es una filosofía de vida que nos impulsa, como personas o entidades, a ayudar a los demás; es aquella vocación interna que nos compromete con el otro a satisfacer sus necesidades, sus requerimientos, sus expectativas e inquietudes. En la administración distrital, entendemos el servicio al ciudadano(a) como nuestra razón de ser. Los ciudadanos y las ciudadanas son el eje de la gestión pública, y todos y cada uno de nuestros esfuerzos deben estar dirigidos a satisfacer sus necesidades y a garantizar su bienestar individual y colectivo (Convenio USTA - ICONTEC, 2012).

De acuerdo con lo expresado por el Ministerio de Tecnologías de la Información y las Comunicaciones, el trámite es un conjunto o serie de pasos 0 acciones reguladas por el Estado, que los usuarios deben efectuar para adquirir un derecho o cumplir con una obligación prevista o autorizada por la ley.

En cuanto al concepto de cliente, la NTCGP 1000:2009 lo define así: "3.12 Cliente. Organización, entidad o persona que recibe un producto y/o servicio. Nota: Para efectos de esta norma, y de conformidad con la Ley 872 de 2003, el término cliente incluye a los destinatarios, usuarios o beneficiarios" (Agencia Nacional de Defensa Jurídica del Estado, 2014).

La mejora continua consiste en incrementar la eficacia de un sistema aplicando la política de calidad, los 
objetivos de calidad, los resultados de las verificaciones de inspección, el análisis de los datos, las acciones correctivas y preventivas y la revisión de la dirección. Actividad recurrente para aumentar la capacidad para cumplir los requisitos. La mejora continua del desempeño global de la organización debería ser un objetivo permanente de esta.

Sistemas de gestión de la calidad (SGC). Se refieren a aquella parte del sistema de gestión de la organización en el logro de resultados, en relación con los objetivos de calidad, para satisfacer las necesidades, expectativas y requisitos de las partes interesadas, según corresponda.

\section{METODOLOGÍA}

La investigación se abordó desde una perspectiva cuantitativa con relación a su propósito,; es deductiva, ya que está delimitada por la teoría (marco teórico de la investigación), el contexto (resultado de la investigación-encuesta); y por su entendimiento es aplicativa, dado que el método cuantitativo tiene como ventaja que puede brindar información fiable y estructurada que permite sopesar la realidad del problema planteado por la investigación, proponiendo lineamientos para la mejora continua del sistema de gestión de la calidad en las citadas entidades.

Se empleó el método empírico estadístico mediante la utilización del instrumento o técnica de recolección de datos denominado encuesta, la cual fue aplicada a los usuarios mayores de edad (adultos) del sistema de transporte masivo público TransMilenio y de la Secretaría Secretaría Distrital de Movilidad (SDM). La encuesta fue sistematizada con el software: SAP Lumira versión del software: 1.25.1
La metodología diseñada para determinar el grado de satisfacción de los usuarios con base en la percepción de los servicios prestados por las dos entidades responsables de la movilidad en el Distrito Capital se realizó en siete momentos, así:

- Primero: Revisión de las teorías de los autores Deming, Ishikawa y Juran, como apoyo a la investigación, y elaboración de sus propios conceptos para cada una de las categorías utilizadas.

- Segundo: Establecimiento de las variables y de los indicadores, armonizando las teorías de los autores relacionados, para así construir el instrumento luego de revisar las fuentes de información secundarias, como medios de comunicación, resultados de las encuestas de satisfacción del ciudadano aplicadas por estas entidades, PQRS, resultados de las auditorías internas de calidad y accidentalidad vehicular.

- Tercero: Construcción del instrumento-encuesta para la toma de la información de los usuarios de los servicios. Para el análisis de cada uno de los indicadores o interrogantes, se hace necesario retomar la escala de Likert adoptada para este estudio dentro de la metodología y su equivalencia entre los valores absolutos de 1 a 5 , así como la aceptación o no del encuestado manifestando el grado en que está de acuerdo o en desacuerdo con el indicador.

- Cuarto: Validación del instrumento por cinco (5) expertos acreditados.

- Quinto: Realización de la prueba piloto.

- Sexto: Aplicación de instrumento.

- Séptimo: Tabulación y procesamiento con instrumentos estadísticos automatizados seleccionados. 


\section{RESULTADOS Y DISCUSIÓN}

El comportamiento de los indicadores o de las afirmaciones con su media aritmética y desviación estándar se presentan en la tabla 2.

Tabla 2. Tabla de media aritmética y desviación estándar de los indicadores. Secretaría Distrital de Movilidad.

\begin{tabular}{|c|c|c|}
\hline $\begin{array}{l}\text { Descripción de interrogantes } \\
\text { del instrumento }\end{array}$ & 䄈 & : 婿 \\
\hline $\begin{array}{l}\text { 1. La información suministrada de los trámites } \\
\text { y/o servicios que le prestó la entidad en el } \\
\text { momento en que usted la requirió. }\end{array}$ & 2,74 & 1,26 \\
\hline $\begin{array}{l}\text { 2. Divulgación de los requisitos para los } \\
\text { diferentes trámites y/o servicios que presta la } \\
\text { entidad. }\end{array}$ & 2,71 & 1,26 \\
\hline $\begin{array}{l}\text { 3. Información que proporcionó la entidad para } \\
\text { realizar el trámite y/o servicio. }\end{array}$ & 2,87 & 1,37 \\
\hline $\begin{array}{l}\text { 4. Grado en que el trámite y/o servicio realizado } \\
\text { en la entidad cumplió sus expectativas. }\end{array}$ & 2,30 & 1,23 \\
\hline 5. Claridad de la página web de la entidad. & 2,49 & 1,23 \\
\hline $\begin{array}{l}\text { 6. Actualización constante que ofrece el sitio } \\
\text { web de la entidad para la realización de un } \\
\text { trámite y/o servicio. }\end{array}$ & 2,29 & 1,27 \\
\hline $\begin{array}{l}\text { 7. Corrección que ofrece la entidad a las fallas } \\
\text { que se presentan en los trámites y/o servicios. }\end{array}$ & 2,13 & 1,16 \\
\hline $\begin{array}{l}\text { 8. Facilidad para realizar sus trámites y/o } \\
\text { servicios con la incorporación de las nuevas } \\
\text { tecnologías (botón de pagos, digitalización de } \\
\text { la información y consulta de comparendos en } \\
\text { línea, entre otros). }\end{array}$ & 2,75 & 1,30 \\
\hline $\begin{array}{l}\text { 9. Atención oportuna de la entidad a su petición, } \\
\text { queja, reclamo o solicitud. }\end{array}$ & 2,35 & 1,01 \\
\hline $\begin{array}{l}\text { 10. Respuesta detallada de la entidad a su } \\
\text { petición queja, reclamo o solicitud. }\end{array}$ & 2,33 & 1,11 \\
\hline $\begin{array}{l}\text { 11. Mejora que la entidad muestra para la } \\
\text { prestación de trámites y/o servicios. }\end{array}$ & 2,33 & 1,23 \\
\hline $\begin{array}{l}\text { 12. Facilidad para acceder a los trámites y/o } \\
\text { servicios que presta la entidad. }\end{array}$ & 2,41 & 1,31 \\
\hline $\begin{array}{l}\text { 13. Amabilidad de las personas que forman parte } \\
\text { de la prestación del servicio en la entidad. }\end{array}$ & 3,29 & 1,37 \\
\hline
\end{tabular}

Fuente: estudio propio resultado de los datos recolectados.
Como se observa, las percepciones de los usuarios frente al grado en que el trámite y/o servicio realizado en la entidad llenó sus expectativas, la claridad de la página web de la entidad, la actualización constante que ofrece el sitio web de la entidad para la realización de un trámite y/o servicio y la corrección que ofrece la entidad a las fallas que se presentan en los trámites y/o servicios tuvieron resultados entre 2,13 y 2,49 en la escala de 1 a 5 , lo que da a entender que hay niveles altos de insatisfacción, puesto que el valor promedio apenas está por debajo del $50 \%$ del valor ideal. Así mismo, se observa una dispersión relativamente baja entre $(1,09$ y 1,31$)$ respectivamente, lo cual significa que la opinión de los usuarios es altamente homogénea, es decir, que hay una alta proporción de los usuarios que están de acuerdo con la calificación promedio.

Igualmente, la percepción de los usuarios frente a "la amabilidad de las personas que hacen parte de la prestación del servicio en la entidad", resultó con una media de 3,29 en la escala de 1 a 5, lo que da a entender que hay cierto nivel de satisfacción. Así mismo, se observa una dispersión relativamente baja $(1,37)$, lo cual significa que la opinión de los usuarios es altamente homogénea, es decir, que hay una alta proporción de los usuarios que están de acuerdo con la calificación promedio.

En la SDM, la mayoría de los usuarios prefiere adelantar los trámites y/o servicios los viernes, con una participación del 33,70 \%, y los lunes, con un 18,84 \%. El día de menor preferencia es el miércoles con 9,42\% de participación. Así mismo, el 68,48 \% prefiere realizar los trámites en el SuperCADE de la calle 13, seguido del SuperCADE de la avenida Las Américas, con el $12,32 \%$ sobre el total.

La salida de vehículos de Patios es el trámite que mayor cantidad de veces se realiza, con un 39,13\%, seguido del acuerdo de pago, con 18,12\% (ver tabla 3 ). 
Tabla 3. Trámites y servicios por SUPERCADE

\begin{tabular}{|l|r|r|r|r|r|r|}
\hline \multicolumn{7}{|c|}{ Analisis de tramites y/o servicios por supercade } \\
\hline \multicolumn{1}{|c|}{ tramite y/o servicio } & CAD & CALLE 13 & $\begin{array}{c}\text { Supercade 20 } \\
\text { DE JULIO }\end{array}$ & $\begin{array}{c}\text { Supercade } \\
\text { AMERICAS }\end{array}$ & $\begin{array}{c}\text { Supercade } \\
\text { SUBA }\end{array}$ & $\begin{array}{c}\text { Total } \\
\text { general }\end{array}$ \\
\hline Acuerdo de Pago & $0.00 \%$ & $10.51 \%$ & $2.17 \%$ & $2.90 \%$ & $2.54 \%$ & $18.12 \%$ \\
\hline Agilización tramite & $0.00 \%$ & $0.36 \%$ & $0.00 \%$ & $0.00 \%$ & $0.00 \%$ & $0.36 \%$ \\
\hline Cambio de placa & $0.00 \%$ & $0.00 \%$ & $0.00 \%$ & $0.36 \%$ & $0.00 \%$ & $0.36 \%$ \\
\hline Consulta de comparendo & $0.00 \%$ & $0.00 \%$ & $0.00 \%$ & $0.00 \%$ & $1.45 \%$ & $1.45 \%$ \\
\hline Corrección de comparendo & $0.72 \%$ & $0.00 \%$ & $0.00 \%$ & $0.00 \%$ & $1.45 \%$ & $2.17 \%$ \\
\hline Curso de sensibilización por conducir en & $0.00 \%$ & $3.62 \%$ & $0.00 \%$ & $0.00 \%$ & $0.00 \%$ & $3.62 \%$ \\
\hline estado de embriaguez & $0.00 \%$ & $2.90 \%$ & $0.36 \%$ & $2.90 \%$ & $0.00 \%$ & $6.16 \%$ \\
\hline Curso sobre normas de tránsito & $0.00 \%$ & $1.45 \%$ & $0.00 \%$ & $2.17 \%$ & $0.36 \%$ & $3.99 \%$ \\
\hline Desembargo de propiedades & $0.00 \%$ & $1.81 \%$ & $0.00 \%$ & $0.00 \%$ & $0.00 \%$ & $1.81 \%$ \\
\hline Foto Comparendo & $0.00 \%$ & $0.00 \%$ & $0.36 \%$ & $0.00 \%$ & $0.00 \%$ & $0.36 \%$ \\
\hline Inscripción en el RUNT & $0.00 \%$ & $0.36 \%$ & $0.00 \%$ & $0.00 \%$ & $0.00 \%$ & $0.36 \%$ \\
\hline Movilización de Vehículo & $0.36 \%$ & $5.07 \%$ & $1.45 \%$ & $2.54 \%$ & $1.81 \%$ & $11.23 \%$ \\
\hline Pago de comparendo & $1.09 \%$ & $0.72 \%$ & $0.00 \%$ & $0.00 \%$ & $1.81 \%$ & $3.62 \%$ \\
\hline Pago de impuesto de vehículo & $0.00 \%$ & $0.00 \%$ & $0.36 \%$ & $0.36 \%$ & $1.45 \%$ & $2.17 \%$ \\
\hline Pago de multa & $0.00 \%$ & $0.00 \%$ & $0.00 \%$ & $0.00 \%$ & $0.36 \%$ & $0.36 \%$ \\
\hline Pago electrónico de comparendo & $0.00 \%$ & $39.13 \%$ & $0.00 \%$ & $0.00 \%$ & $0.00 \%$ & $39.13 \%$ \\
\hline Salida de Vehículo de Patios & $0.00 \%$ & $0.36 \%$ & $0.00 \%$ & $0.72 \%$ & $0.00 \%$ & $1.09 \%$ \\
\hline Tramitar derecho de petición & $0.36 \%$ & $1.45 \%$ & $0.00 \%$ & $0.36 \%$ & $0.36 \%$ & $2.54 \%$ \\
\hline Tramitar licencia de conducción & $0.36 \%$ & $0.36 \%$ & $0.00 \%$ & $0.00 \%$ & $0.00 \%$ & $0.72 \%$ \\
\hline Tramitar reporte de declaraciones y pagos & $0.00 \%$ & $0.36 \%$ & $0.00 \%$ & $0.00 \%$ & $0.00 \%$ & $0.36 \%$ \\
\hline Traspaso de propiedad & $2.90 \%$ & $68.48 \%$ & $4.71 \%$ & $12.32 \%$ & $11.59 \%$ & $100.00 \%$ \\
\hline Total general & & & & & & \\
\hline
\end{tabular}

Fuente: autores (2015).

Con relación a la "facilidad de acceder a los trámites que presta la entidad", se ratifica la tendencia de tener una percepción de total desacuerdo en razón a que presenta el 55,79\% en las respuestas con calificación de 1 y 2 , reitera el porcentaje de las respuestas con calificación de 3 de 20,29 \% y presenta una disminución del porcentaje de preguntas sin calificación NS/NR a un $2,54 \%$ (ver figura 1 ).
En el figura 2, con relación a la "facilidad para realizar sus trámites y/o servicios con la incorporación de las nuevas tecnologías", se evidencia un porcentaje que refleja un valor muy relevante: el de las respuestas sin calificación NS/NR, con 47,46\%, seguido de un $14,13 \%$, correspondiente a quienes calificaron este aspecto con 3 , y del 10,87 \% de usuarios que dieron 1 de calificación, esto es, que estuvieron totalmente en desacuerdo. 
Javier Díaz Acosta, Gladys Espitia Peña, Blanca Ofir Murillo Solarte

Figura 1. Facilidad para acceder a los trámites y/o servicios que presta la entidad

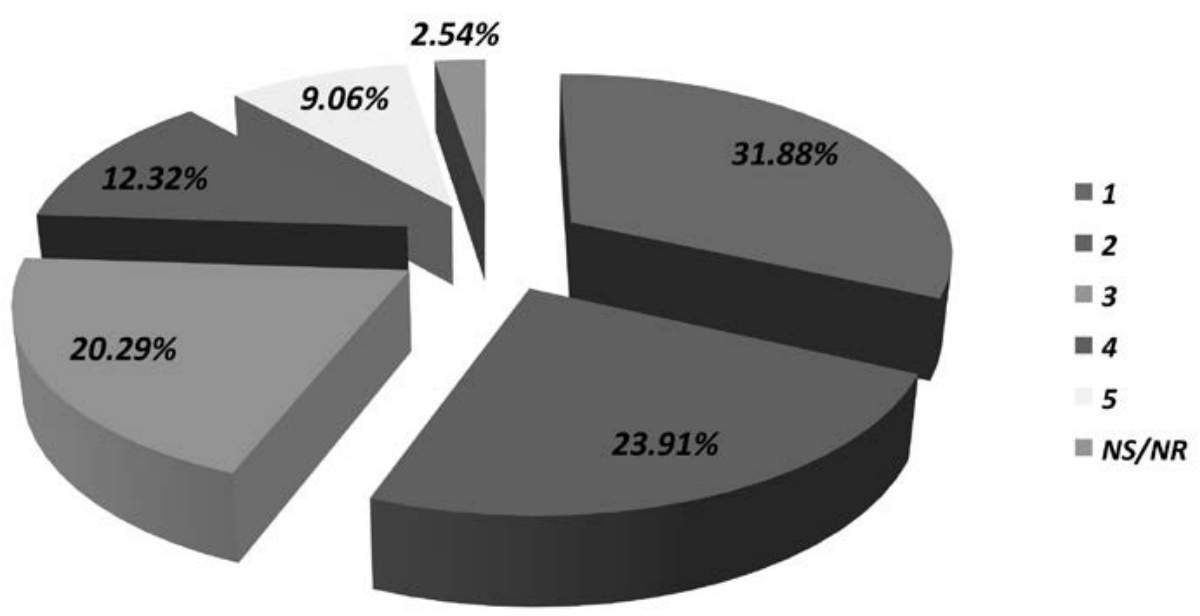

Fuente: autores (2015).

Figura 2. Facilidad para realizar sus trámites y/o servicios con la incorporación de las nuevas tec
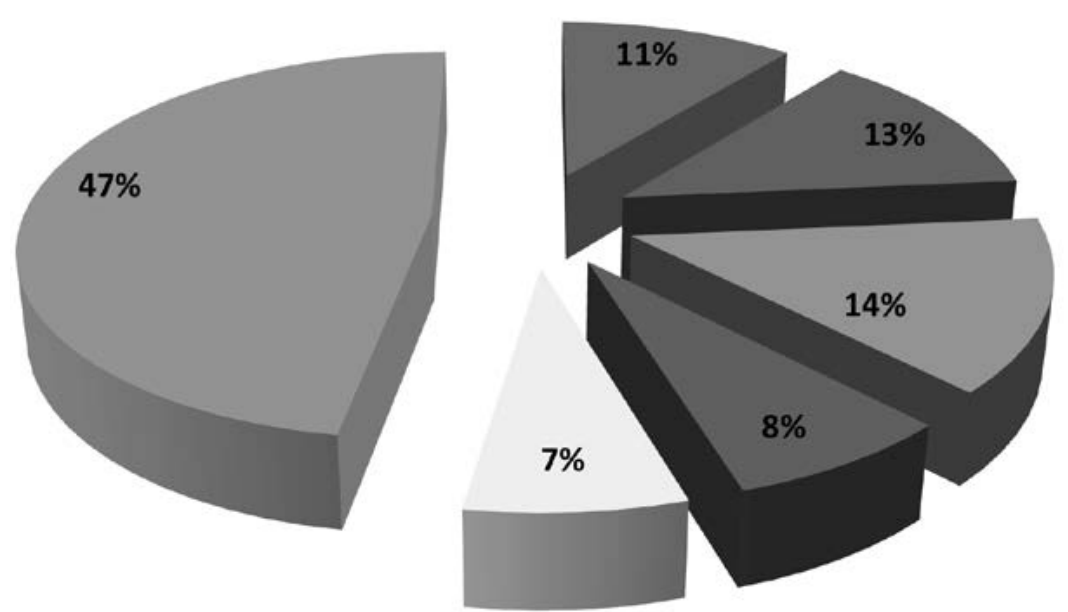
Respecto a la "claridad de la página web de la entidad", los resultados muestran una percepción que conserva la tendencia de este grupo de indicadores, dado que el porcentaje de la población que calificó 3 es del $23,21 \%$, el que de quienes calificaron este aspecto con 4 es del $13,39 \%$, el de aquellos que dieron calificación de 5 es del 8,04 \%, que sumados representan el $44,64 \%$ de los encuestado (ver figura 3 ).

Con relación a la "atención oportuna de la entidad a su petición, queja, reclamo o solicitud", la figura 4 muestra que la percepción conserva la tendencia de este grupo de indicadores dado que el porcentaje de la población que calificó este aspecto con 3 es del
$35,80 \%$, el porcentaje de quienes lo calificaron 2 es del $27,16 \%$, y el de aquellos que dieron 2 como calificación es del 25,93\%, porcentajes que sumados representan el 88,89\% de los usuarios que no están de acuerdo con esta afirmación.

La mejora con mayor índice de selección fue "agilidad en los procedimientos", con un 56,52 \% de participación por parte de toda la población en general; en segundo lugar se encontró la descentralización de los trámites, con un porcentaje de $15,94 \%$, seguido de la divulgación de estos, con un porcentaje de 14,49\% (ver figura 5).

Figura 3. Claridad de la página web de la entidad

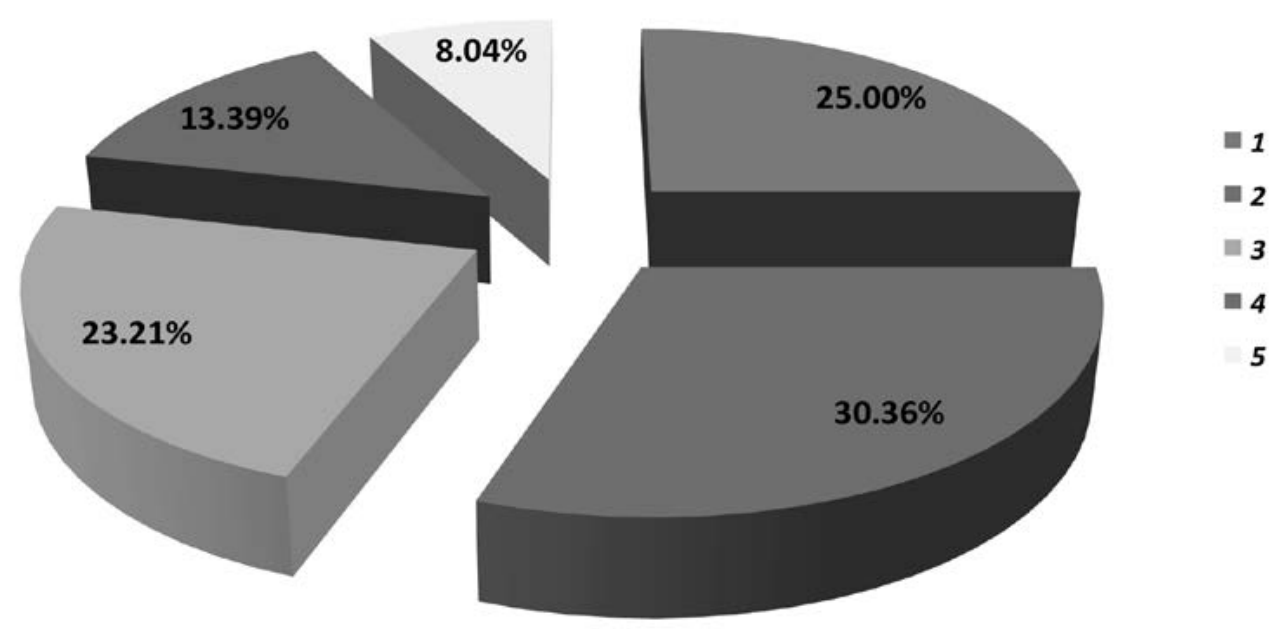

Fuente: autores (2015). 
Javier Díaz Acosta, Gladys Espitia Peña, Blanca Ofir Murillo Solarte

Figura 4. Atención oportuna de la entidad a su petición, queja, reclamo o solicitud.

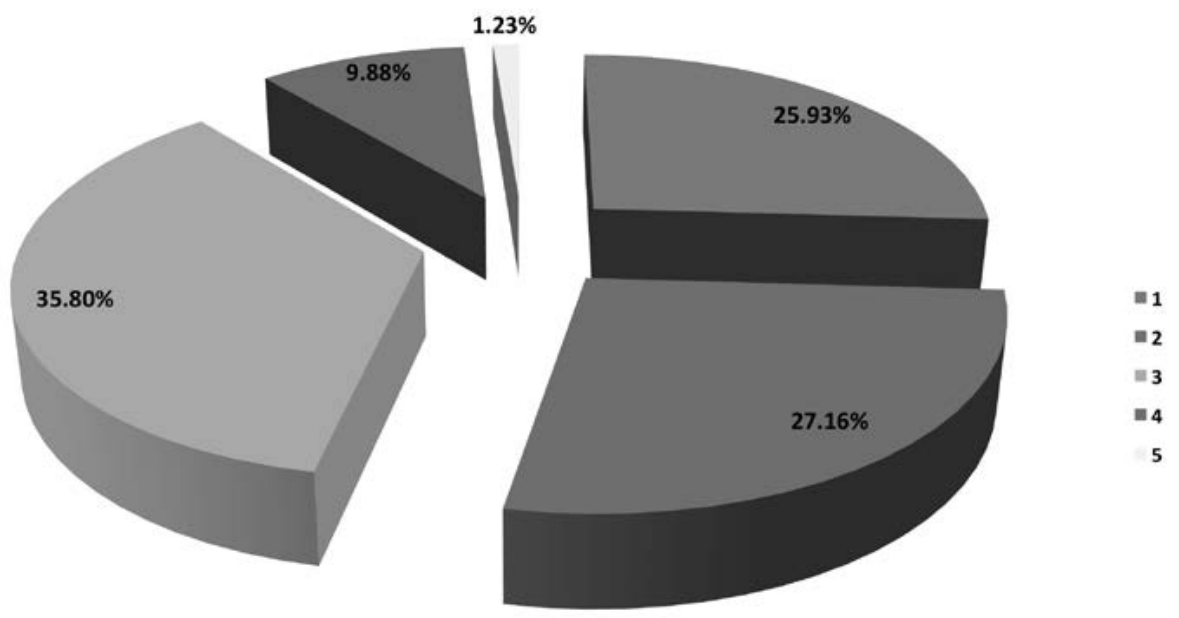

Fuente: autores (2015).

Figura 5. Aspectos que aporta a la gestión de calidad

Cuales de los siguientes aspectos aportarían mas a la gestión de calidad de la SDM

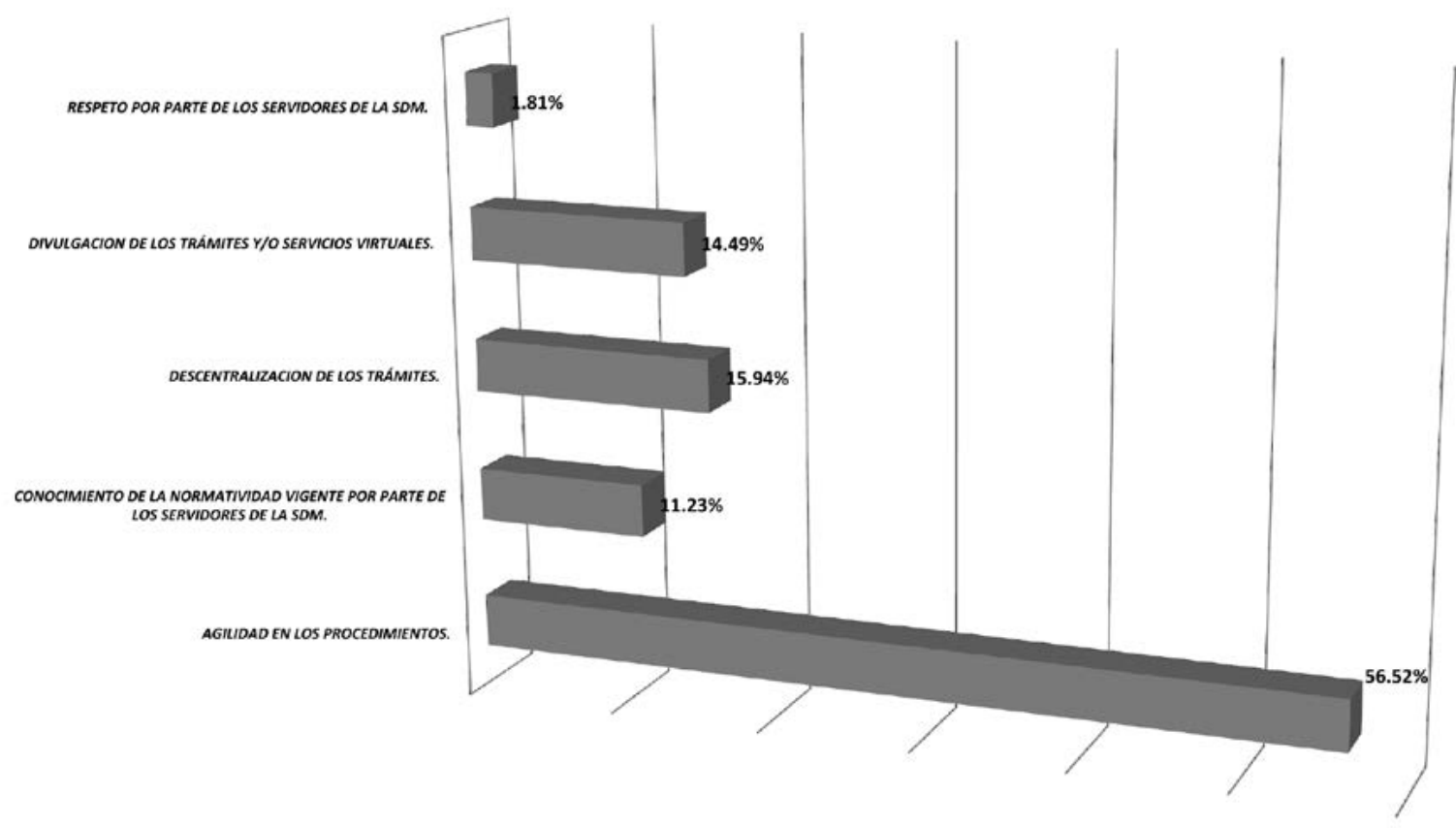

Fuente: autores (2015). 
Los valores considerados dentro del estudio con relación a la media aritmética y a la desviación estándar se establecen en la tabla 4.

Tabla 4. Tabla de media aritmética y desviación estándar de los indicadores de TransMilenio S. A.

\begin{tabular}{|c|c|c|}
\hline $\begin{array}{l}\text { Descripción de interrogantes del } \\
\text { instrumento }\end{array}$ & 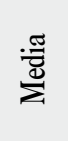 & 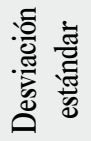 \\
\hline $\begin{array}{l}\text { 1. La información suministrada de los } \\
\text { servicios }\left(^{*}\right) \text { que le prestó TransMilenio en } \\
\text { el momento que usted la requirió. }\end{array}$ & 2,47 & 1,12 \\
\hline $\begin{array}{l}\text { 2. Amplia divulgación de los requisitos } \\
\text { para acceder a los servicios }\left({ }^{*}\right) \text { que presta } \\
\text { TransMilenio. }\end{array}$ & 2,48 & 1,15 \\
\hline $\begin{array}{l}\text { 3. Confiabilidad de la información que le } \\
\text { proporcionó TransMilenio acerca de los } \\
\text { diferentes servicios }(*) \text {. }\end{array}$ & 2,62 & 1,21 \\
\hline $\begin{array}{l}\text { 4. Grado en que el servicio }(*) \text { recibido de } \\
\text { TransMilenio llenó sus expectativas. }\end{array}$ & 2,14 & 0,99 \\
\hline $\begin{array}{l}\text { 5. Claridad de la página web de } \\
\text { TransMilenio. }\end{array}$ & 3,29 & 1,05 \\
\hline $\begin{array}{l}\text { 6. Actualización constante que ofrece el sitio } \\
\text { web de TransMilenio para la consulta de los } \\
\text { servicios. }\end{array}$ & 3,19 & 1,08 \\
\hline $\begin{array}{l}\text { 7. Corrección que ofrece TransMilenio a las } \\
\text { fallas que se presentan en la prestación del } \\
\text { servicio }(*) \text {. }\end{array}$ & 2,21 & 0,94 \\
\hline $\begin{array}{l}\text { 8. Facilidad para utilizar los servicios }\left({ }^{*}\right) \text { con } \\
\text { la incorporación de las nuevas tecnologías } \\
\text { (pantallas informativas, mapas táctiles, } \\
\text { lectores digitales de tarjetas, entre otros). }\end{array}$ & 2,86 & 1,31 \\
\hline $\begin{array}{l}\text { 9. Atención oportuna de TransMilenio a su } \\
\text { petición, queja, reclamo o solicitud. }\end{array}$ & 2,14 & 1,23 \\
\hline $\begin{array}{l}\text { 10. Respuesta detallada de TransMilenio a } \\
\text { su petición queja, reclamo o solicitud. }\end{array}$ & 2 & 1,07 \\
\hline $\begin{array}{l}\text { 11. Mejora que TransMilenio muestra para } \\
\text { la prestación de sus servicios. }\left({ }^{*}\right)\end{array}$ & 2,38 & 0,96 \\
\hline $\begin{array}{l}\text { 12. Facilidad para acceder a los servicios }(*) \\
\text { que presta TransMilenio. }\end{array}$ & 2,71 & 1,09 \\
\hline $\begin{array}{l}\text { 13. Amabilidad de las personas que forman } \\
\text { parte de la prestación del servicio }\left(^{*}\right) \text { en } \\
\text { TransMilenio. }\end{array}$ & 3,02 & 1,17 \\
\hline
\end{tabular}

Fuente: estudio propio resultado de los datos recolectados.
De la tabla 4 se puede establecer que las percepciones de los usuarios frente a "la información suministrada de los servicios (*) que le prestó TransMilenio en el momento que usted lo requirio", "la amplia divulgación de los requisitos para acceder a los servicios (*) que presta TransMilenio", "el grado en que el servicio (*) recibido de TransMilenio llenó sus expectativas", "la corrección que ofrece TransMilenio a las fallas que se presentan en la prestación del servicio", "la atención oportuna de TransMilenio a su petición, queja, reclamo o solicitud", "la respuesta detallada de TransMilenio a su petición queja, reclamo o solicitud" y "la mejora que TransMilenio muestra para la prestación de sus servicios. (*)" presentan una media entre 2 y 2,48 en la escala de 1 a 5 , lo que da a entender que hay niveles altos de insatisfacción, puesto que el valor promedio apenas está por debajo del $50 \%$ del valor ideal. Así mismo, se observa una dispersión relativamente baja entre $(0,96$ y 1,23$)$ respectivamente, lo cual significa que hay una alta proporción de los usuarios que están de acuerdo con la calificación promedio.

Finalmente, se observa que la percepción de los usuarios frente a "la claridad de la página web de TransMilenio", "la actualización constante que ofrece el sitio web de TransMilenio para la consulta de los servicios" y "la amabilidad de las personas que forman parte de la prestación del servicio (*) en TransMilenio" resultó con una media entre 3,02 y 3,29 en la escala de 1 a 5, lo que da a entender que hay niveles satisfacción y se observa una dispersión relativamente baja entre $(1,05$ y 1,17) respectivamente.

Los usuarios utilizan el sistema de lunes a viernes con un $73,45 \%$, mientras que el nivel de uso baja a un $13,45 \%$ los sábados, y para los domingos y festivos tiene una participación del 13,09\%.

Del total de las encuestas realizadas en todas las franjas horarias y días, se encontró que el portal con mayor densidad de población es el Portal Norte, con 
una participación del 14,86 \% del total de la muestra. Esto indica que la población usuaria de TransMilenio se encuentra principalmente en este portal. El Portal Sur tiene una participación del 13,41\%. Los portales Eldorado, Américas y Suba continúan en orden de importancia de participación. Los sábados los portales con mayor recurrencia de población son Ricaurte (NQS) y Eldorado. El portal con mayor población los domingos y festivos es el Portal Suba.

Como se puede ver en la figura 6, las respuestas calificadas con puntajes 1 y 2 muestran un aumento en sus porcentajes de $21,74 \%$, y $31,52 \%$, que suman el $53,26 \%$, lo que evidencia una percepción en desacuerdo en general sobre el grado en que el servicio recibido llenó las expectativas sobre la prestación de los servicios de TransMilenio S. A.

En la figura 7, las respuestas calificadas con puntajes 1 y 2 muestran un aumento en sus porcentajes de 31,52 $\%$ y $33,33 \%$, que suman el $63,85 \%$, lo que evidencia una percepción en desacuerdo en general sobre el grado en que el servicio recibido llenó las expectativas sobre la prestación de los servicios de TransMilenio S. A.

Figura 6. La información suministrada de los servicios $\left({ }^{*}\right)$ que le prestó

TransMilenio en el momento que usted lo requirió

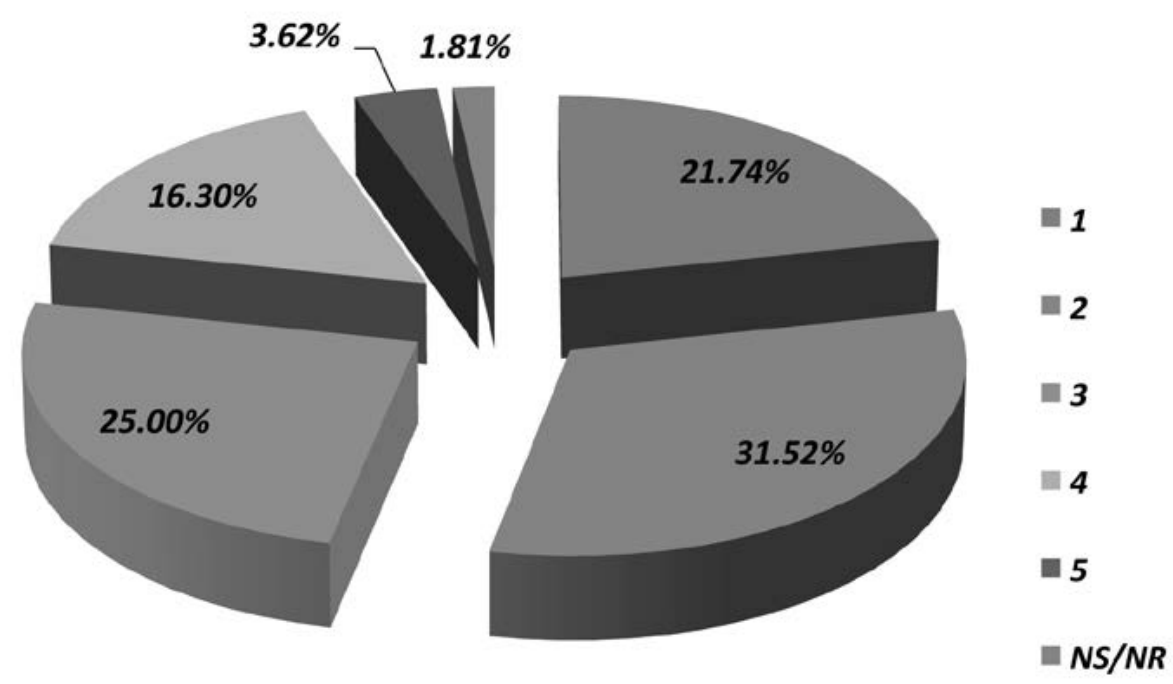

Fuente: autores (2015). 
Fiǵura 7. Grado en que el servicio (*) recibido de TransMilenio llenó sus expectativas

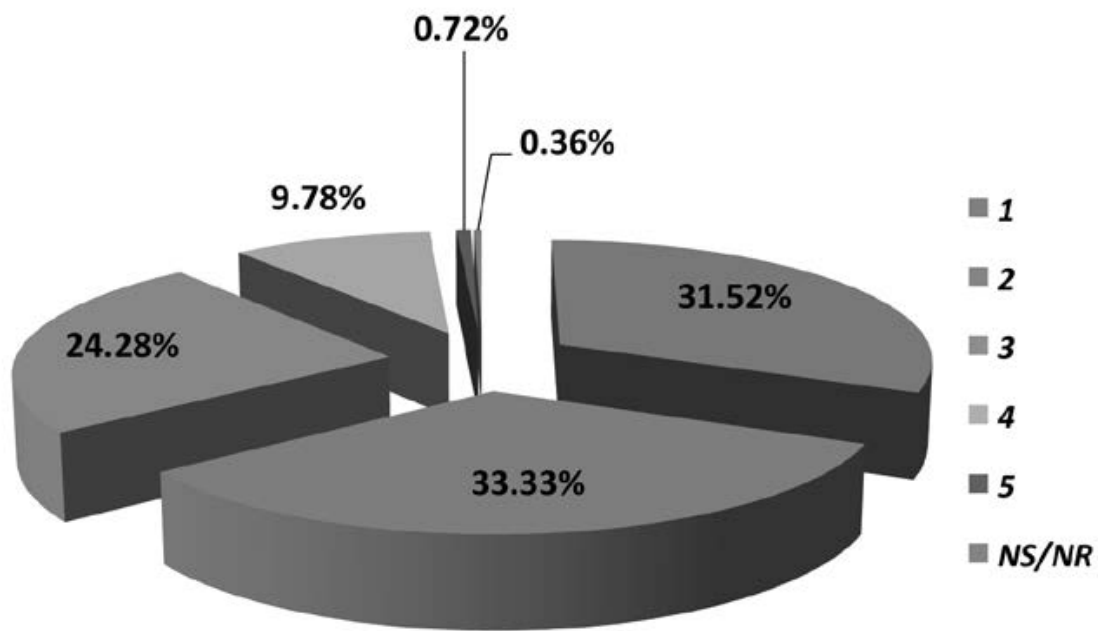

Fuente: autores (2015).

La figura 8 presenta la percepción sobre la "confia- de calificaciones con 1, 2 y 3, de 20,73 \%, 28,36\% bilidad de la información que proporcionó TransMilenio $\quad$ y 26,18 \% respectivamente, lo cual significa que el S. A.”. Esta figura muestra que las calificacio- usuario tiene alguna concordancia con el servicio nes con 4 tienden a incrementarse, pasando a un prestado y el indicador relacionado. $16,73 \%$, conservando la tendencia de los porcentajes

Figura 8. Confiabilidad de la información que proporcionó TransMilenio acerca de los diferentes servicios

\section{$8.00 \%$}
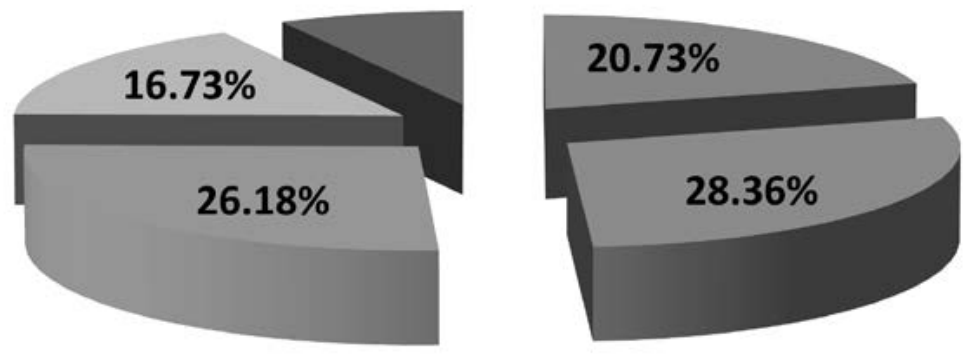

2

3

Fuente: autores (2015). 
En la figura 9 se presenta la percepción que tienen los usuarios al indicador "respuesta detallada de TransMilenio a su petición, queja, reclamo o solicitud"; se observa que solamente entre las respuestas calificadas con 1,2 y 3 se encuentra el $88,57 \%$ de los encuestados, por lo que se evidencian la insatisfacción y el desacuerdo total frente al indicador en mención.

Fiǵura 9. Respuesta detallada de TransMilenio a su petición, queja, reclamo o solicitud.

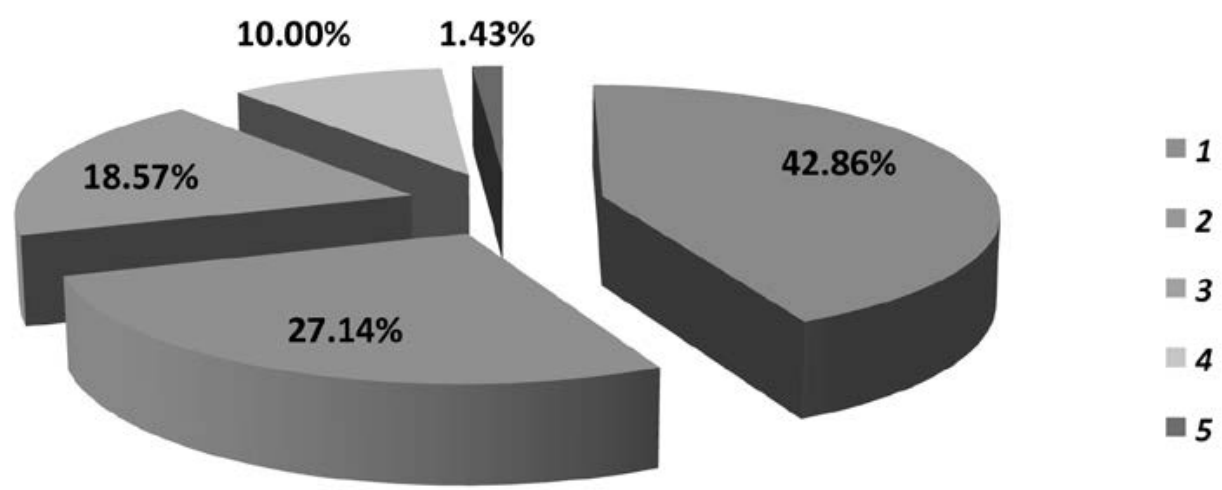

Fuente: autores (2015).

Según la figura 10, sobre el indicador "la mejora que TransMilenio muestra para la prestación de sus servicios", se denota una percepción de los usuarios al desacuerdo, con una participación del $32 \%$ de las repuestas calificadas con 2 y con un $31,27 \%$ de las repuestas calificadas con 3, para un total de participación de las calificaciones 1, 2 y 3 del 82,18\%, por lo que se considera que los usuarios están en desacuerdo con el indicador 0 con la afirmación.

Figura 10. Mejora en la prestación de servicios
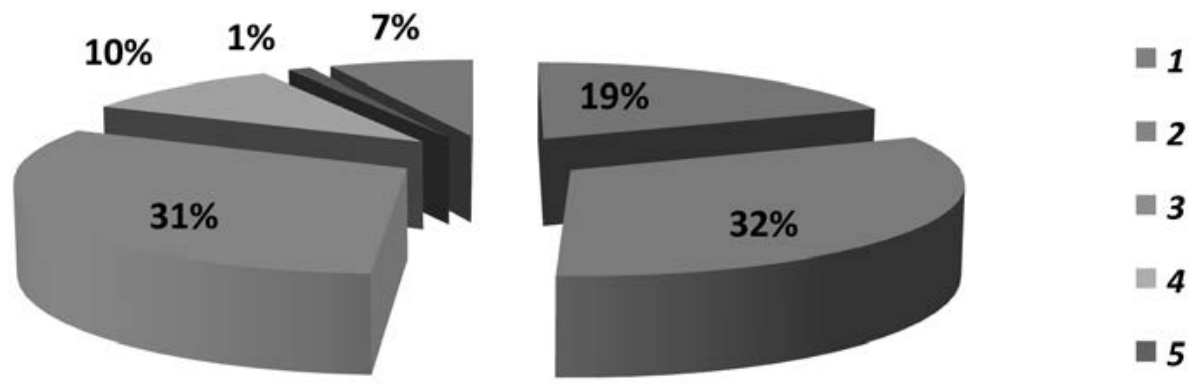

$\square S / N R$

Fuente: autores (2015). 


\section{PROPUESTA DE LINEAMIENTOS}

Producto del resultado de la presente investigación, se presentan los lineamientos y las recomendaciones distritales, así:

Tabla 5. Secretaría Distrital de Movilidad - SDM

\begin{tabular}{|c|c|}
\hline \multicolumn{2}{|c|}{ LINEAMIENTOS vs. RECOMENDACIONES } \\
\hline LINEAMIENTOS & RECOMENDACIONES \\
\hline $\begin{array}{l}\text { Dar respuestas de fondo y coherentes a las peticiones, las quejas y los } \\
\text { reclamos, todo dentro de los plazos legales. }\end{array}$ & \multirow{3}{*}{$\begin{array}{l}\text { Conformar un equipo interdisciplinario con conocimiento integral } \\
\text { de la entidad para el tratamiento prioritario que se le debe dar a los } \\
\text { trámites y/o servicios, las peticiones, las quejas, los reclamos y las } \\
\text { solicitudes, tanto los que ingresan por el aplicativo de correspondencia } \\
\text { de la entidad como los radicados mediante el Sistema Distrital de } \\
\text { Quejas y Soluciones (SDQS) de la Alcaldía Mayor de Bogotá D.C.. } \\
\text { El equipo ha de estar liderado por un funcionario del más alto nivel, } \\
\text { que se encargue de concientizar e interiorizar a todos los servidores } \\
\text { públicos sobre la importancia de esta labor para el mejoramiento } \\
\text { continuo de la gestión; así mismo, el líder será el encargado de realizar } \\
\text { un análisis de causas y el tratamiento de estas. } \\
\text { Fortalecer los canales de interacción efectiva entre los servidores } \\
\text { públicos de las diferentes dependencias responsables de los PQRS en } \\
\text { la entidad y la mitigación y tratamiento de los riesgos que se generen } \\
\text { con dicha labor. }\end{array}$} \\
\hline $\begin{array}{l}\text { Mantener actualizado y llevar una trazabilidad del registro de la } \\
\text { totalidad de las peticiones, las quejas, los reclamos, las sugerencias y } \\
\text { solicitudes de información que reciba la Secretaría por los diferentes } \\
\text { canales integrados, tanto las que ingresan por el aplicativo de } \\
\text { correspondencia de la entidad, como los radicados por medio del } \\
\text { Sistema Distrital de Quejas y Soluciones (SDQS) de la Alcaldía Mayor } \\
\text { de Bogotá D.C., realizando un análisis de causas y el tratamiento de } \\
\text { estas, contribuyendo así a la adecuada toma de decisiones. }\end{array}$ & \\
\hline $\begin{array}{l}\text { Diseñar e implementar mecanismos de interacción efectiva entre los } \\
\text { servidores públicos responsables de los procesos de peticiones, quejas, } \\
\text { reclamos y solicitudes con las demás dependencias de la Secretaría } \\
\text { Distrital de Movilidad, con el fin de lograr mayor eficacia en la } \\
\text { solución de los requerimientos de los usuarios y prevenir los riesgos } \\
\text { que pueden generarse en desarrollo de dicho proceso. }\end{array}$ & \\
\hline $\begin{array}{l}\text { Efectuar la modernización del portal web y de las oficinas encargadas } \\
\text { de los trámites y/o servicios, atención de peticiones, quejas, reclamos } \\
\text { y solicitudes, las cuales deben tener ubicación estratégica y cuya } \\
\text { señalización debe ser visible en las diferentes sedes de acceso directo } \\
\text { a los usuarios, para darles el trámite correspondiente. }\end{array}$ & \multirow{2}{*}{$\begin{array}{l}\text { Diseñar, desarrollar e implementar plataformas, aplicativos y sistemas } \\
\text { de información interoperables, que permitan que los usuarios } \\
\text { apoyados en las herramientas tecnológicas tengan un fácil y ágil acceso } \\
\text { a la información de los trámites y/o servicios ofrecidos por la entidad. } \\
\text { Que la oficina de radicación de correspondencia cuente con un punto } \\
\text { de acceso a los usuarios, ubicado en un lugar visible y debidamente } \\
\text { señalizado. }\end{array}$} \\
\hline $\begin{array}{l}\text { Contar con aplicativos, plataformas y sistemas de información } \\
\text { interoperables para mantener actualizada, disponible y de fácil acceso } \\
\text { la información para los usuarios. }\end{array}$ & \\
\hline \multirow[b]{2}{*}{$\begin{array}{l}\text { Facilitar y promover la participación en la gestión de los usuarios y las } \\
\text { organizaciones sociales para que realicen control social. }\end{array}$} & $\begin{array}{l}\text { Divulgar, en medios de comunicación internos y externos, las metas } \\
\text { y los avances en la gestión de la SDM, informando sobre los nuevos } \\
\text { planes, programas y proyectos que se adelanten, incentivando la } \\
\text { participación y el control social al respecto. }\end{array}$ \\
\hline & $\begin{array}{l}\text { Publicación permanente de los trámites y/o servicios y sus requisitos } \\
\text { a los usuarios para fomentar la participación ciudadana por medio } \\
\text { de la creación de grupos focales en cada una de las localidades } \\
\text { que permitan efectuar el control social y que sirvan para la } \\
\text { implementación de mejoras en la gestión. }\end{array}$ \\
\hline
\end{tabular}




\begin{tabular}{|c|c|}
\hline \multicolumn{2}{|c|}{ LINEAMIENTOS vs. RECOMENDACIONES } \\
\hline LINEAMIENTOS & RECOMENDACIONES \\
\hline $\begin{array}{l}\text { Soportar y divulgar los trámites y/o servicios prestados en los canales } \\
\text { de interacción ciudadana (presencial, telefónica y virtual). Instalar } \\
\text { en los SuperCADES buzones de quejas, reclamos, sugerencias y } \\
\text { felicitaciones. Y en la página web, habilitar sitios para divulgación } \\
\text { permanentemente de los trámites y/o servicios y sus requisitos. }\end{array}$ & $\begin{array}{l}\text { Instalar en los SuperCADES buzones de quejas, reclamos, } \\
\text { sugerencias y felicitaciones. Y en la página web, habilitar sitios para } \\
\text { divulgación permanentemente de los trámites y/o servicios y sus } \\
\text { requisitos. } \\
\text { Aplicar una encuesta permanente que evalúe la satisfacción de los } \\
\text { usuarios frente a la prestación de los servicios. }\end{array}$ \\
\hline \multirow{3}{*}{$\begin{array}{l}\text { Diseñar e implementar estrategias de comunicación, divulgación e } \\
\text { interacción con la ciudadanía para el fácil acceso y el conocimiento } \\
\text { de los trámites y/o servicios, sus requerimientos y las diferentes } \\
\text { campañas que adelante la entidad. }\end{array}$} & $\begin{array}{l}\text { Fortalecer los canales de comunicación, de tal manera que la } \\
\text { prestación del trámite y/o servicio sea ágil, eficiente y efectivo, para } \\
\text { lograr así que los servidores y las servidoras puedan interactuar con los } \\
\text { usuarios de manera directa, sencilla y eficaz. }\end{array}$ \\
\hline & $\begin{array}{l}\text { Por ser la Secretaría Distrital de Movilidad cabeza del sector, se } \\
\text { recomienda que lidere y coordine estrategias para el manejo articulado } \\
\text { de un plan de medios del sector movilidad. }\end{array}$ \\
\hline & $\begin{array}{l}\text { Fomentar la cultura ciudadana incentivando el respeto al peatón y a } \\
\text { las señales de tránsito y promoviendo el no exceso de velocidad, esto } \\
\text { con el propósito de minimizar o reducir los índices de mortalidad, } \\
\text { morbilidad y accidentalidad en la ciudad. }\end{array}$ \\
\hline $\begin{array}{l}\text { Incluir en el programa de capacitación el fortalecimiento del } \\
\text { conocimiento sobre la normatividad vigente, los trámites y/o servicios } \\
\text { y sus términos para todos los servidores, dándole prioridad a los que } \\
\text { interactúan con el usuario y a los encargados de los PQRS. }\end{array}$ & $\begin{array}{l}\text { Se recomienda que en el Programa de Capacitación Institucional } \\
\text { (PIC) se incluyan las actualizaciones normativas a todos los servidores } \\
\text { de la entidad, especialmente a los que interactúen con los usuarios. }\end{array}$ \\
\hline $\begin{array}{l}\text { Implementar, en los procesos de atención al ciudadano, protocolos } \\
\text { que incluyan atributos de buen servicio comunes a todos los canales } \\
\text { establecidos por la entidad. }\end{array}$ & $\begin{array}{l}\text { Fomentar la cultura de servicio al ciudadano-usuarios por medio } \\
\text { de protocolos de obligatorio cumplimiento apoyados en un grupo } \\
\text { gestores y facilitadores internos que realicen seguimiento y evaluación } \\
\text { permanente para la prestación de los servicios en forma equitativa, } \\
\text { con igualdad de trato para la ciudadanía. }\end{array}$ \\
\hline $\begin{array}{l}\text { Prestar una atención a los usuarios con calidez, amabilidad, con un } \\
\text { trato respetuoso, digno, especializado y humano. }\end{array}$ & \multirow{2}{*}{$\begin{array}{l}\text { Fortalecer los procesos de selección, inducción y reinducción de los } \\
\text { servidores que atienden en los puntos de contacto o que interactúan } \\
\text { directamente con los usuarios, que cuenten con los atributos exigidos } \\
\text { previamente por la entidad para el desarrollo de dicha labor. }\end{array}$} \\
\hline $\begin{array}{l}\text { Contar de manera permanente con el personal idóneo y suficiente que } \\
\text { atienda a la ciudadanía, tanto en los puntos de contacto como en el } \\
\text { interior de la SDM. }\end{array}$ & \\
\hline $\begin{array}{l}\text { Diseñar e implementar instrumentos que permitan evaluar la } \\
\text { satisfacción de los usuarios frente a los servicios, que permitan } \\
\text { plantear estrategias y acciones de mejora continua en la prestación } \\
\text { tales servicios. }\end{array}$ & $\begin{array}{l}\text { Aplicar periódicamente encuestas que midan la percepción de la } \\
\text { satisfacción, de manera integral, de todos los trámites y/o servicios } \\
\text { que presta la Secretaría Distrital de Movilidad, cuyos resultados } \\
\text { contribuyan al diseño y a la implementación de estrategias y acciones } \\
\text { de mejora continua en la prestación de tales servicios. }\end{array}$ \\
\hline $\begin{array}{l}\text { Desarrollar e implementar la política de racionalización de trámites } \\
\text { y/o servicios. }\end{array}$ & $\begin{array}{l}\text { Implementar un minucioso estudio de tiempos y movimientos de } \\
\text { las actividades y los desplazamientos que requiere cada trámite y/o } \\
\text { servicio prestado por la entidad. Y con base en los resultados de dicho } \\
\text { estudio, rediseñar los procesos para optimizar el uso de recursos y así } \\
\text { dar respuesta oportuna y eficaz a los usuarios. }\end{array}$ \\
\hline
\end{tabular}




\begin{tabular}{|l|l|}
\hline \multicolumn{2}{|c|}{ LINEAMIENTOS vs. RECOMENDACIONES } \\
\hline \multicolumn{1}{|c|}{ LINEAMIENTOS } & \multicolumn{1}{c|}{ RECOMENDACIONES } \\
\hline $\begin{array}{l}\text { Establecer alianzas estratégicas para contribuir a la mejora continua y } \\
\text { optimizar trámites y/o servicios ofertados a la ciudadanía. }\end{array}$ & $\begin{array}{l}\text { Promover la generación de mesas de trabajo, convenios, alianzas con } \\
\text { las entidades del orden nacional, distrital, públicas y privadas, para } \\
\text { lograr establecer e implementar políticas para intercambios de saberes } \\
\text { y suministro de información. }\end{array}$ \\
\hline $\begin{array}{l}\text { Lograr que haya una mayor cobertura y acceso por parte de } \\
\text { los usuarios a los trámites y/o servicios que presta la SDM, } \\
\text { permitiéndoles resolver sus inquietudes, necesidades y expectativas } \\
\text { de forma ágil, oportuna y veraz. }\end{array}$ & $\begin{array}{l}\text { Implementar en los diferentes SuperCADES del Distrito los trámites } \\
\text { y/o servicios a cargo de la Secretaría Distrital de Movilidad, así como } \\
\text { todos los que se encuentren delegados en terceros, para dar a los } \\
\text { usuarios un servicio oportuno y de fácil acceso. }\end{array}$ \\
\hline $\begin{array}{l}\text { Impulsar la cultura del control y el autocontrol fomentando la mejora } \\
\text { continua en todos los servidores de la entidad. }\end{array}$ & $\begin{array}{l}\text { Incentivar la cultura del control y el autocontrol fomentando la mejora } \\
\text { continua en todos los servidores de la entidad. }\end{array}$ \\
\hline
\end{tabular}

Fuente: autores (2015).

Seguidamente, se presenta la tabla que relaciona los lineamientos y las recomendaciones para TransMilenio S. A., así:

Tabla 6. Transmilenio

\begin{tabular}{|c|c|}
\hline \multicolumn{2}{|c|}{ LINEAMIENTOS vs. RECOMENDACIONES } \\
\hline LINEAMIENTOS & RECOMENDACIONES \\
\hline $\begin{array}{l}\text { Dar respuestas de fondo, coherentes y dentro de los plazos legales a } \\
\text { las peticiones, quejas y reclamos de los usuarios. }\end{array}$ & \multirow{3}{*}{$\begin{array}{l}\text { Conformar un equipo interdisciplinario con conocimiento integral } \\
\text { de la entidad para el tratamiento prioritario que se les debe dar a } \\
\text { los servicios, las peticiones, las quejas, los reclamos y las solicitudes, } \\
\text { tanto los que ingresan por el aplicativo de correspondencia de la } \\
\text { entidad como los radicados mediante el Sistema Distrital de Quejas y } \\
\text { Soluciones (SDQS) de la Alcaldía Mayor de Bogotá D.C.. } \\
\text { Este equipo deberá estar liderado por un funcionario del más } \\
\text { alto nivel, que se encargue de concientizar e interiorizar a todos } \\
\text { los servidores públicos sobre la importancia de esta labor para el } \\
\text { mejoramiento continuo de la gestión; así mismo, ese líder será el } \\
\text { encargado de realizar un análisis de causas y el tratamiento de estas; } \\
\text { de igual forma, fortalecerá los canales de interacción efectiva entre } \\
\text { los servidores públicos responsables de los PQRS en las diferentes } \\
\text { dependencias de la entidad y la mitigación y tratamiento de los } \\
\text { riesgos que se generen con dicha labor. }\end{array}$} \\
\hline $\begin{array}{l}\text { Mantener actualizado y llevar una trazabilidad del registro de la } \\
\text { totalidad de las peticiones, las quejas, los reclamos, las sugerencias } \\
\text { y solicitudes de información de las fuentes existentes, para darles el } \\
\text { tratamiento oportuno y adecuado. }\end{array}$ & \\
\hline $\begin{array}{l}\text { Diseñar e implementar mecanismos de interacción efectiva entre } \\
\text { los servidores públicos responsables de los procesos de peticiones, } \\
\text { quejas, reclamos y solicitudes con las demás dependencias de } \\
\text { TransMilenio S. A., con el fin de lograr mayor eficacia en la solución } \\
\text { de los requerimientos de los ciudadanos y prevenir los riesgos que } \\
\text { pueden generarse en desarrollo de dichos procesos. }\end{array}$ & \\
\hline $\begin{array}{l}\text { Contar con aplicativos, plataformas y sistemas de información } \\
\text { interoperables para mantener actualizada, disponible y de fácil acceso } \\
\text { la información para los usuarios. }\end{array}$ & $\begin{array}{l}\text { TransMilenio S. A. diseñará, desarrollará e implementará plataformas, } \\
\text { aplicativos y sistemas de información interoperables, que permitan } \\
\text { que los usuarios, apoyados en las herramientas tecnológicas, tengan } \\
\text { un fácil y ágil acceso a la información de los trámites y/o servicios a los } \\
\text { usuarios. }\end{array}$ \\
\hline
\end{tabular}




\begin{tabular}{|c|c|}
\hline \multicolumn{2}{|c|}{ LINEAMIENTOS vs. RECOMENDACIONES } \\
\hline LINEAMIENTOS & RECOMENDACIONES \\
\hline \multirow{5}{*}{$\begin{array}{l}\text { Facilitar y promover la participación en la gestión de los usuarios y las } \\
\text { organizaciones sociales para que realicen control social. }\end{array}$} & $\begin{array}{l}\text { Instalar buzones en sitios estratégicos de las estaciones o portales con } \\
\text { el ánimo de generar una mayor interacción con los usuarios. }\end{array}$ \\
\hline & $\begin{array}{l}\text { Socializar y publicar permanentemente los servicios y sus requisitos } \\
\text { para mejorar el acceso a los servicios que ofrece TransMilenio. }\end{array}$ \\
\hline & $\begin{array}{l}\text { Divulgar, en los medios de comunicación internos y externos, las } \\
\text { metas y los avances en la gestión de TransMilenio S. A., informando } \\
\text { sobre los nuevos planes, programas y proyectos que se adelanten, la } \\
\text { realización de grupos focales que permitan efectuar el control social y } \\
\text { que sirvan para la generación de propuestas de mejora. }\end{array}$ \\
\hline & $\begin{array}{l}\text { Ubicar buzones de peticiones, quejas, reclamos y sugerencias en } \\
\text { sitios estratégicos de estaciones y portales para los usuarios y, además, } \\
\text { desarrollar e implementar un acceso o enlace en la página web con el } \\
\text { fin de darles el trámite correspondiente. }\end{array}$ \\
\hline & $\begin{array}{l}\text { Soportar y divulgar en los canales de interacción ciudadana } \\
\text { (presencial, telefónico y virtual) y en los medios de comunicación los } \\
\text { servicios que presta TransMilenio S. A. }\end{array}$ \\
\hline \multirow{2}{*}{$\begin{array}{l}\text { Diseñar e implementar estrategias de comunicación, divulgación e } \\
\text { interacción con la ciudadanía para el fácil acceso y conocimiento de los } \\
\text { trámites y/o servicios, sus requerimientos y las diferentes campañas } \\
\text { que adelante la entidad. }\end{array}$} & $\begin{array}{l}\text { Fortalecer, por medio de cartillas, protocolos, manuales y estrategias } \\
\text { de divulgación de los servicios, los canales de comunicación para } \\
\text { buscar que los servidores y las servidoras puedan interactuar directa, } \\
\text { sencilla y eficazmente. }\end{array}$ \\
\hline & $\begin{array}{l}\text { Liderar y coordinar estrategias para el manejo articulado de un plan de } \\
\text { medios con la SDM. }\end{array}$ \\
\hline $\begin{array}{l}\text { Incluir en el programa de capacitación de TransMilenio S. A. el } \\
\text { fortalecimiento del conocimiento dirigido a los servidores y a las } \\
\text { servidoras. }\end{array}$ & $\begin{array}{l}\text { Capacitar y divulgar constantemente a todos los servidores sobre la } \\
\text { normatividad vigente, los servicios, los requerimientos y las mejores } \\
\text { prácticas, dándoles prioridad a los que interactúan con el usuario y a } \\
\text { los encargados de los PQRS. }\end{array}$ \\
\hline $\begin{array}{l}\text { Implementar, en los procesos de atención al ciudadano, mecanismos } \\
\text { que fortalezcan los atributos de buen servicio comunes a todos los } \\
\text { canales establecidos por la entidad. }\end{array}$ & $\begin{array}{l}\text { Crear un programa de cultura de servicio al ciudadano-usuarios y } \\
\text { contar con un grupo de facilitadores internos que realicen seguimiento } \\
\text { y evaluación permanente a dicho servicio, para la prestación de los } \\
\text { servicios en forma equitativa, con igualdad de trato para la ciudadanía. }\end{array}$ \\
\hline $\begin{array}{l}\text { Contar de manera permanente con el personal idóneo y suficiente que } \\
\text { atienda a la ciudadanía. }\end{array}$ & $\begin{array}{l}\text { Fortalecer los procesos de selección, inducción y reinducción de los } \\
\text { servidores que atienden en las diferentes estaciones o troncales, que } \\
\text { cuenten con los atributos exigidos previamente por la entidad para } \\
\text { el desarrollo de dicha labor, con el fin de prestar una atención a los } \\
\text { ciudadanos con calidez, amabilidad, con un trato respetuoso, digno, } \\
\text { especializado y humano. }\end{array}$ \\
\hline $\begin{array}{l}\text { Implementar instrumentos que permitan evaluar la satisfacción de } \\
\text { los usuarios frente a los servicios que presta TransMilenio, los cuales } \\
\text { permitirán establecer acciones de mejora continua en la prestación de } \\
\text { tales servicios. }\end{array}$ & $\begin{array}{l}\text { Aplicar periódicamente encuestas que midan la percepción de la } \\
\text { satisfacción de manera integral de todos los trámites y/o servicios que } \\
\text { presta TransMilenio S. A., cuyos resultados contribuyen al diseño y a } \\
\text { la implementación de estrategias y acciones de mejora continua en la } \\
\text { prestación de los servicios. }\end{array}$ \\
\hline
\end{tabular}




\begin{tabular}{|c|c|}
\hline \multicolumn{2}{|c|}{ LINEAMIENTOS vs. RECOMENDACIONES } \\
\hline LINEAMIENTOS & RECOMENDACIONES \\
\hline $\begin{array}{l}\text { Desarrollar e implementar la política de racionalización de trámites } \\
\text { y/o servicios. }\end{array}$ & $\begin{array}{l}\text { Implementar un minucioso estudio de tiempos y movimientos de las } \\
\text { actividades y desplazamientos que requiere cada trámite y/o servicio } \\
\text { prestado por la entidad, con base en los resultados de dicho estudio, } \\
\text { rediseñar los procesos para optimizar el uso de recursos y así dar } \\
\text { respuesta oportuna y eficaz a los usuarios. }\end{array}$ \\
\hline \multirow{3}{*}{$\begin{array}{l}\text { Realizar estudios especialmente sobre la FRECUENCIA y } \\
\text { COBERTURA DE LAS RUTAS y la seguridad requeridos por los } \\
\text { usuarios, para determinar así la demanda de los servicios y establecer } \\
\text { la posibilidad de efectuar la ampliación y modernización de las } \\
\text { estaciones y/o de los portales, con el fin de minimizar tiempos y } \\
\text { prestar un servicio efectivo. }\end{array}$} & $\begin{array}{l}\text { TransMilenio S. A. deberá efectuar la ampliación, la modernización } \\
\text { y el mantenimiento permanente de las estaciones y/o de los portales } \\
\text { con señalización visible, para que se facilite el acceso, la movilización } \\
\text { y la seguridad a los usuarios. }\end{array}$ \\
\hline & $\begin{array}{l}\text { TransMilenio S. A. deberá implementar mecanismos para suplir } \\
\text { la FRECUENCIA y la COBERTURA DE LAS RUTAS según } \\
\text { la demanda de estas en las estaciones y/o en los portales de mayor } \\
\text { afluencia. }\end{array}$ \\
\hline & $\begin{array}{l}\text { TransMilenio S. A. deberá diseñar estrategias para ofrecer a } \\
\text { sus usuarios, en las estaciones y/o en los portales, una mayor } \\
\text { SEGURIDAD Y VIGILANCIA. }\end{array}$ \\
\hline $\begin{array}{l}\text { Incentivar la cultura del control y el autocontrol fomentando la mejora } \\
\text { continua en todos los servidores de la entidad. }\end{array}$ & $\begin{array}{l}\text { Adelantar campañas de formación, divulgación y promoción que } \\
\text { permitan la interiorización y la práctica de la cultura del autocontrol, } \\
\text { con el fin de potenciar y generar reconocimiento en los servidores que } \\
\text { adquieren esta disciplina. }\end{array}$ \\
\hline
\end{tabular}

Fuente: autores (2015).

\section{CONCLUSIONES}

- Según el enfoque de Juran, se requiere que la Secretaría Distrital de Movilidad y TransMilenio S. A. identifiquen clara y puntualmente las necesidades de sus usuarios por medio del establecimiento de mecanismos específicos para identificarlas. A la luz de la teoría de Deming, las entidades no han sabido comprender las necesidades actuales de sus usuarios, y mucho menos sus expectativas.

- Partiendo de los resultados, se puede concluir que el liderazgo en la Secretaría Distrital de Movilidad y de TransMilenio S. A. no es el deseado, en la medida en que no se ha propiciado un ambiente interno favorable para generar conciencia hacia la calidad, especialmente cuando su enfoque debe estar dirigido a la satisfacción del cliente. Según lo referenciado por Juran, el liderazgo en calidad es una continuidad de mejora en el producto y una efectiva promoción comercial. Los administradores superiores se deben encargar personalmente de dirigir la revolución de la calidad.

- Al analizar la participación activa de los servidores públicos y/o particulares que ejercen funciones públicas, se tomaron en cuenta la capacitación, el entrenamiento y la amabilidad de los servidores, quienes no cumplen de forma integral con el compromiso que deben tener estos en todos los 
niveles para el logro de los objetivos de estas dos entidades.

- A la luz de la teoría de Juran, la Secretaría Distrital de Movilidad y TransMilenio S. A. deben promover la capacitación de los servidores en la búsqueda de información y su análisis, a fin de permitirles tomar decisiones con base en los hechos, aunado con el concepto de Ishikawa según el cual "el control de calidad empieza con educación y termina con educación". De los resultados obtenidos se concluye que no se evidencia una notoria mejora continua en el SGC en la Secretaría Distrital de Movilidad y en TransMilenio S. A.; su enfoque debería estar orientado a la implementación de maneras más prácticas y mejores para la prestación de los trámites y/o servicios a los usuarios, por ser este un objetivo permanente para aumentar su eficacia, eficiencia y efectividad.

- Por lo anterior, de acuerdo con la teoría de Deming, estas entidades requieren crear constancia en la mejora permanente de productos y servicios, con el objetivo de ser competitivas y mantenerse en el negocio. Así mismo, según el enfoque de Ishikawa, deben llevar a cabo continuamente, como parte de sus actividades de control de calidad, autodesarrollo, desarrollo mutuo, control y mejoramiento por medio del uso de técnicas de control de calidad con la participación de todos sus integrantes. Y acorde con lo propuesto por Juran, han de promover la delegación del control a los más bajos niveles posibles en cada organización, cediendo la responsabilidad del autocontrol a los servidores de los diferentes niveles de autoridad y responsabilidad.

- No se cumplió la hipótesis establecida en el presente trabajo, la cual menciona: "Debido a que la Secretaría Distrital de Movilidad y TransMilenio S. A. tienen cada una su respectivo SGC implementado y/o certificado, bajo NTCGP 1000, sus usuarios están completamente satisfechos con el servicio que prestan dichas entidades". Ahora bien, en atención a los resultados que se evidenciaron en este estudio en relación con la percepción de la satisfacción de los servicios prestados a los usuarios por la Secretaría Distrital de Movilidad y TransMilenio S. A., se estableció el desacuerdo general de los usuarios en la calidad de los trámites y/o servicios prestados por estas entidades respecto a los indicadores 0 a las afirmaciones evaluados, que están directamente relacionados con las teorías base del presente estudio y con los principios de la norma NTCGP:1000-2009.

- Para el presente estudio, se puede concluir que tanto el objetivo general como los objetivos específicos se alcanzaron, ya que se evaluó la percepción de la satisfacción de los usuarios frente a los servicios prestados por las dos entidades y se formularon los lineamientos y las recomendaciones respectivos, los cuales pueden servir a la alta dirección de cada entidad para la toma de decisiones.

- La Secretaría Distrital de Movilidad y TransMilenio S. A., mediante la implementación de los lineamientos sugeridos con sus respectivas recomendaciones, podrían llevar a cabo acciones de mejora en sus respectivos sistemas de gestión de calidad como entidades encargadas de la movilidad en el Distrito Capital.

- El análisis general de los resultados permite concluir que tanto en la Secretaría Distrital de Movilidad como en TransMilenio S. A. no se reflejan con claridad la interrelación, el mantenimiento y la mejora de los procedimientos, procesos y demás elementos del sistema de gestión de calidad, lo cual contribuiría al logro de los objetivos con eficacia, eficiencia y efectividad, con base en 
la teoría de Juran, quién considera que la calidad consiste en la conformidad con las normas, con las especificaciones, con las exigencias o con los procedimientos, enfatizando en las responsabilidades que con respecto a la calidad tienen los servidores, establecidas aquellas en términos de satisfacción de las necesidades de los clientes y en la ausencia de deficiencias, fallas o errores.

\section{REFERENCIAS}

Agencia Nacional de Defensa Jurídica del Estado. (2014). Protocolo de atención al usuario de la Agencia Nacional de Defensa Jurídica del Estado -ANDJE—. Bogotá: ANDJE. Recuperado de goo.gl $/ \mathrm{rCm} 8 \mathrm{WI}$

Alcaldía Mayor de Bogotá, Secretaría General, Dirección Distrital de Servicio al Ciudadano. (junio de 2005). Manual de servicio al ciudadano(a). Recuperado de goo.gl/k1dM4w

Alcaldía Mayor de Bogotá y Secretaría General. (2011). Norma Técnica Distrital del Sistema Integrado de Gestión para las Entidades y Organismos Distritales NTD-SIG 001:2011. Bogotá: Autores. Recuperado de g00.gl/HPd7LJ

(2010)

El servicio al ciudadano en el Distrito Capital. Bogotá. Autores. Recuperado de goo.gl//7GK50

Convenio USTA - ICONTEC. (2012). Efectos de la implementación del sistema de gestión de la calidad en la prestación de los servicios del sector público. Bogotá: Autores.

Departamento Nacional de Planeación. (2013). Programa Nacional de Servicio al Cinudadano. Bogotá: DNP.
Duque, J. (2005). Revisión del concepto de calidad del servicio y sus modelos de medición. Innovar. $R \boldsymbol{\ell}$ vista de Ciencias Sociales y Administrativas, 15(25), 64-80. Recuperado de http://www.redalyc.org/ pdf/818/81802505.pdf

Gaceta Oficial del Distrito Federal. (23 de mayo de 2013). Carta de derechos de los ciudadanos. Gaceta Oficial del Distrito Federal. Recuperado de http:// www.metro.cdmx.gob.mx/imagenes/index/cartaderechosciudad.pdf

Hernández, R., Fernández, C. y Baptista, P. (2010). Metodología de la investigación (5. ${ }^{\mathrm{a}}$ ed.). México: McGraw-Hill.

Dirección Distrital de Servicio al Ciudadano. Subdirección de Calidad del Servicio. (Septiembre de 2013). Informe de atención y direccionamiento de requerimientos a través del sistema distrital de quejas y soluciones SDQS. Bogotá: Alcaldía Mayor de Bogotá. Recuperado de goo.gl/LFHvlJ

Instituto Colombiano de Normas Técnicas y Certificación - ICONTEC. (2011). Norma técnica de calidad en la gestion pública - NTCGP 1000: 2009. Bogotá: ICONTEC.

Juran, J. (1990). Juran y el lideraægo para la calidad. Un manual para ejecutivos. Madrid: Ediciones Díaz de Santos.

Ishikawa, K. (1997). ¿Quées el control total de la calidad? La modalidad japonesa. Bogotá: Editorial Norma.

Juran, J. (1990). Juran y la planificación para la calidad. Madrid: Ediciones Diaz de Santos

Juran, J., Gryna, F. y Bingham, R. (2005). Manual de control de calidad. Barcelona: Editoria Reverté S.A. 
Mejía, J., Poveda, P., Cañón, G. y Bohórquez, L. (2006). Herramientas para implementar un sistema de gestión de calidad. Bogotá: Edición CYGA.

Meulman, J. y Heiser, W. (2011). IBM SPSS Categories 20. Estados Unidos: IBM Corporation.

Munch, L. (1988). Más allá de la excelencia y de la calidad total. México: Editorial Trillas S. A.

Organización Internacional de Normalización (ISO). (2000). Norma técnica colombiana NTC-ISO 9000. Sistemas de gestión de la calidad. Fundamentos y vocabulario. Bogotá: ICONTEC.

Petracci, M. (1998). La medición de la calidad y la satisfacción del ciudadano-usuario de servicios puiblicos privatizados. Buenos Aires: Instituto Nacional de la Administración Pública, Dirección de Estudios e Investigaciones.

Quevedo, A. y Andalaft, A. (2008). Evaluación y propuesta de mejoras de un modelo de atención de usuarios en un servicio público. Revista Economía y Administración, 71, 7-37. Recuperado de goo.gl/ HddnFV

Sabino, C. (1992). El proceso de investigación y sus "momentos". En El proceso de investigación. Caracas: Ed. Panapo.
SAP AG. (2013). Manual de usuario de SAP Lumira. Alemania: SAP AG.

Secretaría de la Función Pública. (2012). Programa Especial de Mejora de la Gestión en la Administración Pública Federal 2008-2012. México: SFP. Recuperado de goo.gl/mcaKqi

Secretaría Distrital de Planeación. (2009). Manual de alianzas público-privadas para el distrito capital, en el marco de la responsabilidad social. Bogotá: Autor. Recuperado de goo.gl/70hlLG

Tamayo y Tamayo, M. (2003). El proceso de la investigación científica (4.a ed.). Bogotá: Editorial LIMUSA Noriega Editores.

Transmilenio S. A. y Alcaldía Mayor de Bogotá. (2013). Informe de Gestión 2012 Transmilenio S. A. Bogotá: Autores.

Vargas, M. y Aldana, L. (2010). Calidad y servicio. Conceptos y herramientas. Bogotá: ECOE Ediciones.

Walton, M. (1988). Cómo administrar con el método Deming. Bogotá: Grupo Editorial Norma. 